\title{
Peripheral chondrosarcoma progression is associated with increased type $X$ collagen and vascularisation
}

\author{
Carlos E. de Andrea • Malgorzata I. Wiweger • \\ Judith V. M. G. Bovée • Salvatore Romeo • \\ Pancras C. W. Hogendoorn
}

Received: 10 August 2011 /Revised: 31 October 2011 / Accepted: 2 November 2011 /Published online: 25 November 2011

(C) The Author(s) 2011. This article is published with open access at Springerlink.com

\begin{abstract}
Endochondral bone formation requires a cartilage template, known as the growth plate, and vascular invasion, bringing osteoblasts and osteoclasts. Endochondral chondrocytes undergo sequences of cell division, matrix secretion, cell hypertrophy, apoptosis, and matrix calcification/mineralisation. In this study, two critical steps of endochondral bone formation, the deposition of collagen X-rich matrix and blood vessel attraction/invasion, were investigated by immunohistochemistry. Fourteen multiple osteochondromas and six secondary peripheral chondrosarcomas occurring in patients with multiple osteochondromas were studied and compared to epiphyseal growth plate samples. Mutation analysis showed all studied patients (expect one) to harbour a germ-line mutations in either EXT1 or EXT2. Here, we described that homozygous mutations in EXT1/EXT2, which are causative for osteochondroma formation, are likely to affect terminal chondrocyte differentiation and vascularisation in the osteocartilaginous interface. Contrastingly, terminal chondrocyte differentiation and vascularisation seem to be unaffected in secondary peripheral chondrosarcoma. In addition, osteochondromas with high vascular density displayed a higher proliferation rate. A similar apoptotic rate was observed in osteochondromas and secondary peripheral chondrosarcomas. Recently, it has been shown that cells with functional EXT1 and EXT2 are outnumbering EXT1/EXT2 mutated cells
\end{abstract}

C. E. de Andrea • M. I. Wiweger · J. V. M. G. Bovée • P. C. W. Hogendoorn $(\bowtie)$

Department of Pathology, Leiden University Medical Center, PO Box 9600, L1-Q, 2300 RC Leiden, The Netherlands e-mail: P.C.W.Hogendoorn@lumc.nl

\section{S. Romeo}

Department of Pathology, Treviso Regional Hospital, Piazza dell' Ospedale 1,

31100 Treviso, Italy in secondary peripheral chondrosarcomas. This might explain the increased type $\mathrm{X}$ collagen production and blood vessel attraction in these malignant tumours.

Keywords Growth plate $\cdot$ Osteochondroma $\cdot$ Peripheral chondrosarcoma · Type X collagen · Angiogenesis · Bone tumour

\section{Introduction}

Elongation of long bones is a complex process that requires a cartilage template, known as the epiphyseal growth plate, and a strict coordination and synchronisation of cell-cell and cellmatrix signalling events [1]. The key events in this process can be divided into two major sequential morphogenesis phases. The first phase is characterised by the proliferation of the growth plate chondrocytes, which maintains the pool of cells needed for bone lengthening. The second phase is a multistep process characterised by the hypertrophy of proliferating chondrocytes and bone formation. Hypertrophic chondrocytes increase their volume and secrete a specialised extracellular matrix rich in type X collagen [2]. The ossifying collagen X-rich matrix attracts blood vessels and bone precursor cells, allowing bone development [3].

The process of endochondral ossification is also observed in cartilaginous tumours [4]. An active endochondral ossification takes place deep to the cartilage cap of osteochondroma and secondary peripheral chondrosarcoma [5].

Osteochondromas are the most common benign bone tumours at childhood and adolescence [6]. They can occur either as a sporadic lesion or multiple tumours in hereditary multiple osteochondromas syndrome (previously known as hereditary multiple exostoses) [7]. Osteochondromas are caused by mutations in either EXT1 or EXT2 genes [7]. 
They are pedunculated or sessile cartilage-capped bony projections from the metaphyses of endochondral bones adjacent to the growth plate [5]. In less than $1 \%$ of patients with sporadic osteochondromas and $1-3 \%$ of patients with multiple osteochondromas at the age of 30-60 years, an osteochondroma may eventually transform into a secondary peripheral chondrosarcoma [8].

Whereas osteochondromas have been linked to homozygous mutations in EXT1 or EXT2 genes, cells with functional EXT1 and EXT2 have been shown to be the predominant subclone in secondary peripheral chondrosarcomas [9].

Mutations in EXT1 have been demonstrated to impair angiogenesis in mice [10] and to affect endochondral bone formation by reducing type $\mathrm{X}$ collagen deposition [11]. Endochondral bone formation has been shown to be affected in the homozygous dak/ext2 zebrafish mutant [12].

$E X T 1$ and EXT2 genes encode enzymes that catalyse the biosynthesis of heparan sulphate. Heparan sulphate is a key component of the extracellular matrix acting as co-receptors for signalling molecules, including vascular endothelial growth factors (VEGF), fibroblast growth factors (FGF), and others $[13,14]$. The impact of mutations in EXT1 or EXT2 genes with regards to production of a collagen X-rich matrix and attraction of blood vessels in osteochondromas and secondary peripheral chondrosarcomas has not been investigated so far.

Here, we describe that terminal chondrocyte differentiation and vascularisation are affected in osteochondromas. Contrastingly, these two critical steps of endochondral bone formation seem to be unaffected in secondary peripheral chondrosarcomas.

\section{Materials and methods}

\section{Patient material}

Paraffin-embedded tissues from 14 osteochondromas and 6 low-grade secondary peripheral chondrosarcomas from patients with multiple osteochondromas, collected between 1991 and 2008, were retrieved from the files of the Leiden University Medical Centre (Table 1). One patient had two tumours from distinct location included in this study. For comparison, paraffin-embedded epiphyseal growth plates $(n=3)$ were obtained from orthopaedic resections for pathological conditions not related to osteochondroma or chondrosarcoma. Clinical information and the thickness of the cartilage cap were obtained from pathology/radiology reports. All samples were handled in a coded fashion, and all procedures were performed according to the ethical guidelines in "Code for Proper Secondary Use of Human Tissue in the Netherlands" (Dutch Federation of Medical Scientific Societies).
Immunohistochemistry

Deparaffinised sections were treated with testicular hyaluronidase ( $2 \mathrm{mg} / \mathrm{ml}$ in 0.1-M Tris saline, $\mathrm{pH} 5.0$; Sigma-Aldrich, $\mathrm{St}$ Louis, MO, USA, $60 \mathrm{~min}$ at $\left.37^{\circ} \mathrm{C}\right)$ and proteinase $\mathrm{K}(5 \mu \mathrm{l} / \mathrm{ml}$ in 0.1-M Tris-buffered saline, $\mathrm{pH}$ 5.0; DakoCytomation, Carpinteria, CA, USA) followed by overnight incubation at $4^{\circ} \mathrm{C}$ with monoclonal antibody to collagen X (clone X53, 1:100, Quartett, Berlin, Germany), as previously described [4, 15]. Monoclonal antibody to CD31 (clone JC70A, 1:10,000, DakoCytomation, Glostrup, Denmark), cleaved caspase-3 (clone 5A1E, 1:100, Cell Signaling Technology, Danvas, MA, USA), and Ki-67 (clone MIB-1, 1:100, Dako, Glostrup, Germany) were used as earlier described [16-18]. The thickness of collagen X-rich matrix was evaluated jointly by two observers (C.E.A. and S.R.). The thickest collagen X stained area was identified in each section and measured by an eye-piece graticule, as described in Fig. 1a. The apoptotic rate was defined as the number of apoptotic cells (positive for caspase-3) out of the total number of nucleated cells. The proliferation rate was determined by counting the numbers of Ki-67-positive cells.

\section{Estimating vascular density by Chalkley counting}

The Chalkley counting method has been previously described in detail [19]. Briefly, the three most vascular areas (hot spots) of each section stained with CD31 were selected and analysed (Fig. 1b). Each vascular hotspot was viewed at $\times 200$ magnification, and a 25-point Chalkley graticule was applied and oriented to permit the maximum number of points to hit in or within the CD31 stained blood vessels $[19,20]$. The Chalkley count for each section was taken as the mean value of the three counts and performed by two observers independently (C.E.A. and J.V.M.G.B.).

\section{Mutation analysis}

Eleven patients were screened by direct sequencing for DNA mutations in the coding sequence of EXT1 or EXT2 genes [21]. After informed consent, DNA was isolated from resected tumours. If no alterations were found, a multiplex ligation-dependent probe amplification assay designed for EXT1 and EXT2 genes was performed to identify possible large deletions, as previously described [22]. Mutation analysis from six patients has been previously reported [15, 23, 24] (Table 1).

Statistical analysis

Results are expressed as the means with a measure of variability (standard deviation, S.D.). Statistical significance was calculated by one-way analysis of variance with 
Table 1 Clinical information of patients with osteochondroma and secondary peripheral chondrosarcoma

\begin{tabular}{|c|c|c|c|c|c|c|}
\hline Case \# & Sample & Age (years) & Gender & Location & $\begin{array}{l}\text { EXT mutation analysis } \\
\text { (type of mutation) }\end{array}$ & $\begin{array}{l}\text { Cartilage cap } \\
\text { thickness (mm) }\end{array}$ \\
\hline L-741 & GP & 2 & M & Femur & - & - \\
\hline L-996 & GP & 8 & M & Femur & - & - \\
\hline L-1142 & GP & 12 & $\mathrm{~F}$ & Tibia & - & - \\
\hline L-1234 & GP & 8 & $\mathrm{~F}$ & Femur & - & - \\
\hline L-298 & $\mathrm{OC}$ & 24 & M & Femur & $\begin{array}{l}\text { EXT1 exon 3: c.1121 G > A, } \\
\text { p.W374X (ns) }\end{array}$ & 6 \\
\hline L-317 & $\mathrm{OC}$ & 31 & M & Tibia & None in $E X T 1$ or $E X T 2^{\mathrm{b}}$ & 4 \\
\hline L-332 & $\mathrm{OC}$ & 25 & M & Femur & None in $E X T 1$ or $E X T 2^{\mathrm{b}}$ & 5.5 \\
\hline L-523 & $\mathrm{OC}$ & 20 & M & Tibia & $\begin{array}{l}\text { EXT1 del codon } 235-239 \\
\quad(\text { del Pro-Leu-Phe-Ser-Lys) }\end{array}$ & 5 \\
\hline L-524 & $\mathrm{OC}$ & 26 & M & Tibia & $\begin{array}{l}\text { EXT1 codon } 164 \mathrm{GAC}>\mathrm{CAC}(\mathrm{Asp}>\mathrm{His}) \\
\text { exon 1: c. } 1212 \mathrm{G}>\mathrm{C}, \mathrm{p} . \mathrm{D} 164 \mathrm{H}^{\mathrm{b}}\end{array}$ & 4.5 \\
\hline L-722 & $\mathrm{OC}$ & 15 & $\mathrm{~F}$ & Radius & EXT2 IVS7+1 G $>\mathrm{A}^{\mathrm{b}}$ & 1.5 \\
\hline L-726 & $\mathrm{OC}$ & 6 & M & Rib & $E X T 2 \operatorname{IVS} 7+1 \mathrm{G}>\mathrm{A}$ & 6 \\
\hline L-841 & $\mathrm{OC}$ & 14 & $\mathrm{~F}$ & Femur & $E X T 2$ deletion exon $6+7(\mathrm{del})^{\mathrm{b}}$ & 8 \\
\hline L-1094 & $\mathrm{OC}$ & 6 & M & Femur & $E X T 2$ del exon $6+7$ & 3 \\
\hline L-1143 & $\mathrm{OC}$ & 39 & M & Femur & NA & 2 \\
\hline L-2029 & OC & 23 & $\mathrm{~F}$ & Femur & EXT2 exon $7: \operatorname{IVS} 7+1 \mathrm{G}>\mathrm{A}$ & 3.5 \\
\hline L-2069 & $\mathrm{OC}$ & 11 & M & Tibia & EXT1 exon 1 c.538_539delAG, p.Ser180fs $X 7^{\text {b }}$ & 5.5 \\
\hline L-2160 & $\mathrm{OC}$ & 48 & $\mathrm{~F}$ & Scapula & EXT1 exon1 c.538_539delAG, p.Ser180fsX17 & 6 \\
\hline L-2350 & $\mathrm{OC}$ & 53 & $\mathrm{~F}$ & Femur & EXT2 exon 7: IVS7+1 G>A & 1 \\
\hline L-951 & $\mathrm{PCH}$ & 24 & M & Fibula & NA & 8 \\
\hline L-2117 & $\mathrm{PCH}$ & 37 & M & Humerus & EXT1 exon 2: c. $1056+1 \mathrm{G}>\mathrm{A}$ & 12 \\
\hline L-114 & $\mathrm{PCH}$ & 39 & M & Femur & EXT2 exon 5: $764 \mathrm{~T}>\mathrm{C}, \mathrm{L} 255 \mathrm{P}(\mathrm{uv})^{\mathrm{b}}$ & 12 \\
\hline L-578 & $\mathrm{PCH}$ & 22 & $\mathrm{~F}$ & Femur & EXT2 deletion exon $6+7$ (del) & 11 \\
\hline L-2254 & $\mathrm{PCH}$ & 33 & $\mathrm{~F}$ & Pelvis & EXT2 exon 6 c. 980 delG, p.Gly327AlafsX5 & 8 \\
\hline L-2372 & $\mathrm{PCH}$ & 54 & M & Rib & NA & 13 \\
\hline
\end{tabular}

$G P$ epiphyseal growth plate, $O C$ osteochondroma, $P C H$ low grade secondary peripheral chondrosarcoma, $N A$ not analysed

${ }^{a}$ Mutation nomenclature was according to the Nomenclature Working Group [30]; $n s$ non-sense, del deletion, $u v$ unclassified variant, $f s$ frame shift, pm polymorphism

${ }^{\mathrm{b}}$ Results of mutation previously reported [15, 23, 24]

Bonferroni's multiple comparison tests. Spearman's rank correlation coefficient was calculated to verify statistical dependence between two variables. Both tests were performed using the SPSS 16.0 software package (IBM, Somers, NY, USA). $P$ values $<0.05$ were considered significant.

\section{Results}

Collagen X-rich matrix in peripheral cartilaginous tumours

The epiphyseal growth plate is organised in columns of stacked chondrocytes (Fig. 2a). The interface between cartilaginous and osseous parts in the growth plate (osteocartilaginous interface) was well defined and formed by hypertrophic chondrocytes immersed in a strong stained collagen X-rich matrix (Fig. 2d). In the growth plate, the collagen X-rich matrix was restricted to the hypertrophic zone and had, on average, $0.8( \pm 0.47) \mathrm{mm}$ thickness.

Osteochondromas showed less structured tissue organisation. The osteocartilaginous interface was also less well defined (Fig. 2b). The collagen X-rich matrix was restricted to the hypertrophic zone and had, on average, $1.5( \pm 1.48)$ $\mathrm{mm}$ thickness. Additionally, in osteochondroma, not all chondrocytes with a hypertrophic morphology expressed type $\mathrm{X}$ collagen (Fig. 2e), and when type $\mathrm{X}$ collagen was present, the staining was mainly seen around the chondrocytes and not across the matrix (Fig. 2e). In osteochondromas, no correlation was found between the age of the patient and the thickness of the collagen X-rich matrix (Spearman's coefficient $=0.25$ ).

Secondary peripheral chondrosarcomas showed no structured tissue organisation (Fig. 2c) and had an average cap thickness of $10 \mathrm{~mm}$. Secondary peripheral 
Fig. 1 Collagen X-rich matrix and vascular density by Chalkley counting. Collagen $\mathrm{X}$-rich matrix produced by hypertrophic chondrocytes was measured from the beginning to the end of the hypertrophic zone (a). Chalkley count reflects the number of grid points that hit CD31 stained vessels (red circles) (b). It is more of an estimate of the relative area than a true vessel count (a scale bar $10 \mu \mathrm{m}$; b scale bars $5 \mu \mathrm{m}$ )
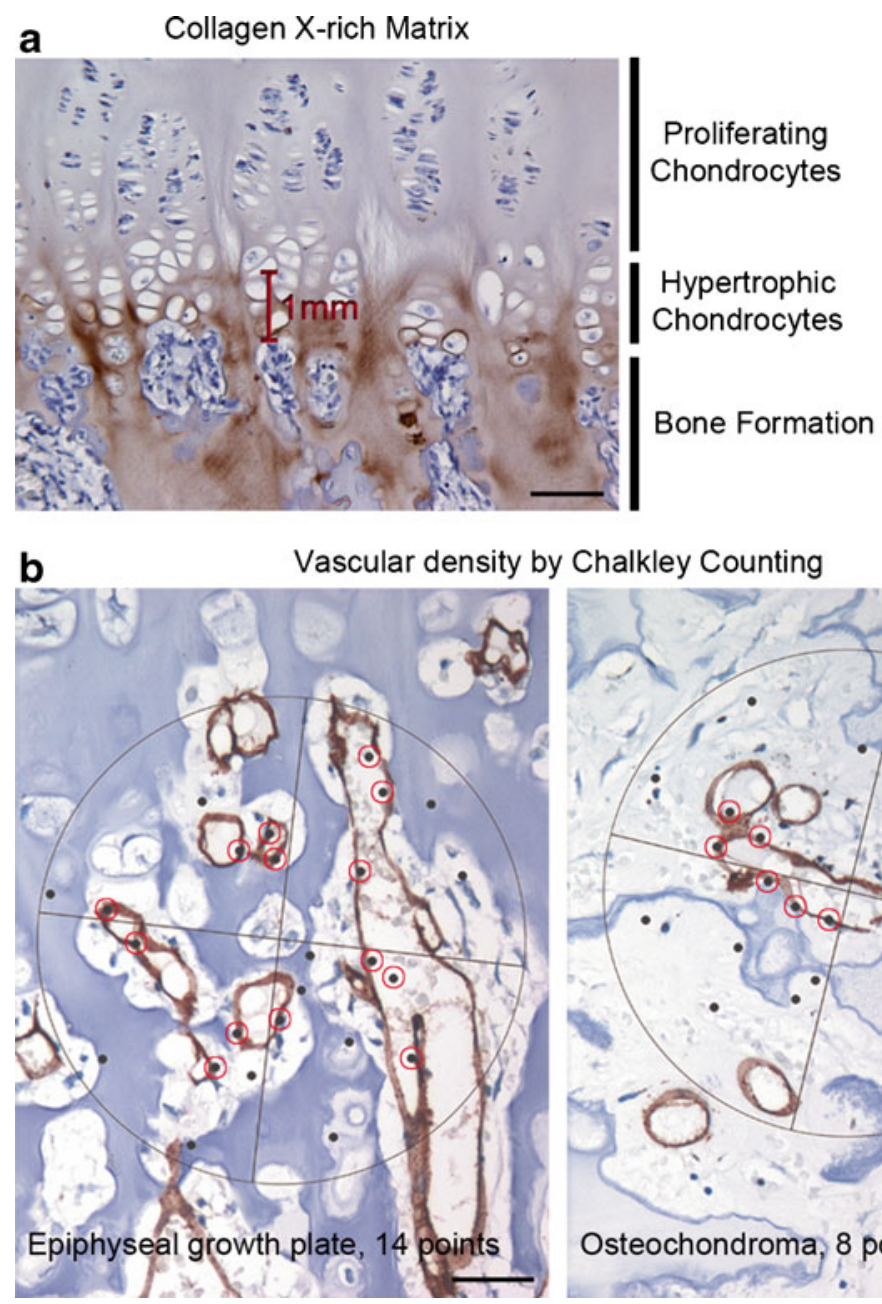

chondrosarcomas showed a thick, uniformly and strongly stained collagen X-rich matrix (Fig. 2f) with an average $6.5( \pm 3.66) \mathrm{mm}$ thickness. Type $\mathrm{X}$ collagen expression in secondary peripheral chondrosarcomas was not restricted to the osteocartilaginous interface but was also detected throughout the extracellular tumour matrix and close to the perichondrium (data not shown). In secondary peripheral chondrosarcomas, no correlation was found between the age of the patient and the thickness of the collagen X-rich matrix (Spearman's coefficient $=0.01$ ).

In osteochondromas and secondary peripheral chondrosarcomas, the thickness of the collagen X-rich matrix correlated with the thickness of the cartilage cap (Spearman's coefficient $=0.63)($ Fig. $2 \mathrm{~g})$.

Similar apoptotic rates were observed in osteochondromas and secondary peripheral chondrosarcomas and had values of $35( \pm 0.16) \%$ vs. $36( \pm 0.15) \%$, respectively $(P=0.847)$.

Vascular density in the ossification area

Invasion of blood vessels is a critical step towards ossification of the collagen X-rich matrix. Strong CD31 staining was observed along the cell membrane of endothelial cells in the epiphyseal growth plate, osteochondroma, and secondary peripheral chondrosarcoma. The median CD31 vascular density in the growth plate osteocartilaginous interface was significantly higher than in osteochondroma, with a value of $10.8( \pm 0.83)$ vs. 6.1 $( \pm 1.79)$, respectively $(P=0.007)$ (Fig. 3a, b, d). Interestingly, no differences in vascularisation of the osteocartilaginous interface were observed between the growth plate and secondary peripheral chondrosarcoma; a value of 10.8 $( \pm 0.83)$ vs. $10( \pm 0.70)$ was, respectively, found $(P=0.464)$ (Fig. 3a, c, d). Moreover, an irregular distribution of blood vessels was identified in the osteocartilaginous interface of osteochondromas and peripheral chondrosarcomas, but not in the epiphyseal growth plates.

In osteochondromas and secondary peripheral chondrosarcomas, no association between the age of the patient and vascular density was found (Spearman's rho correlation coefficient $=0.39$ and 0.27 , respectively).

In osteochondromas, the proliferation rate ranged from $0-24 \%$ in 9 cases to $25-49 \%$ in 5 cases. The cases with a higher proliferation rate (25-49\%) showed a higher 

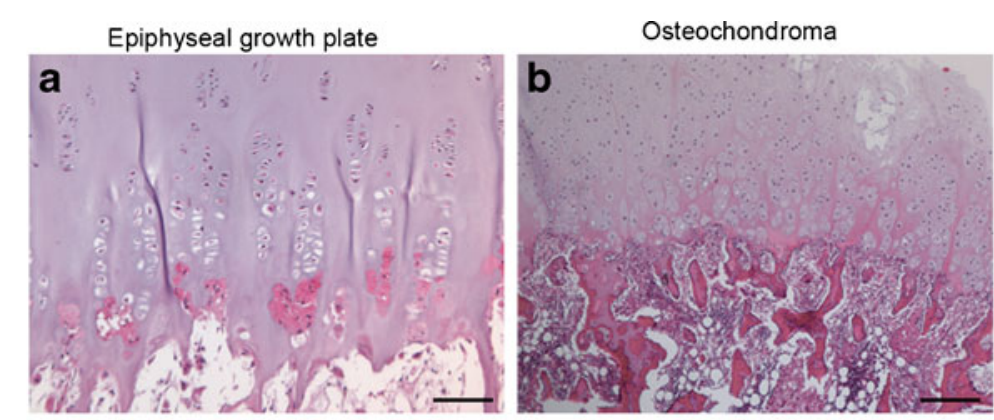

Secondary peripheral chondrosarcoma
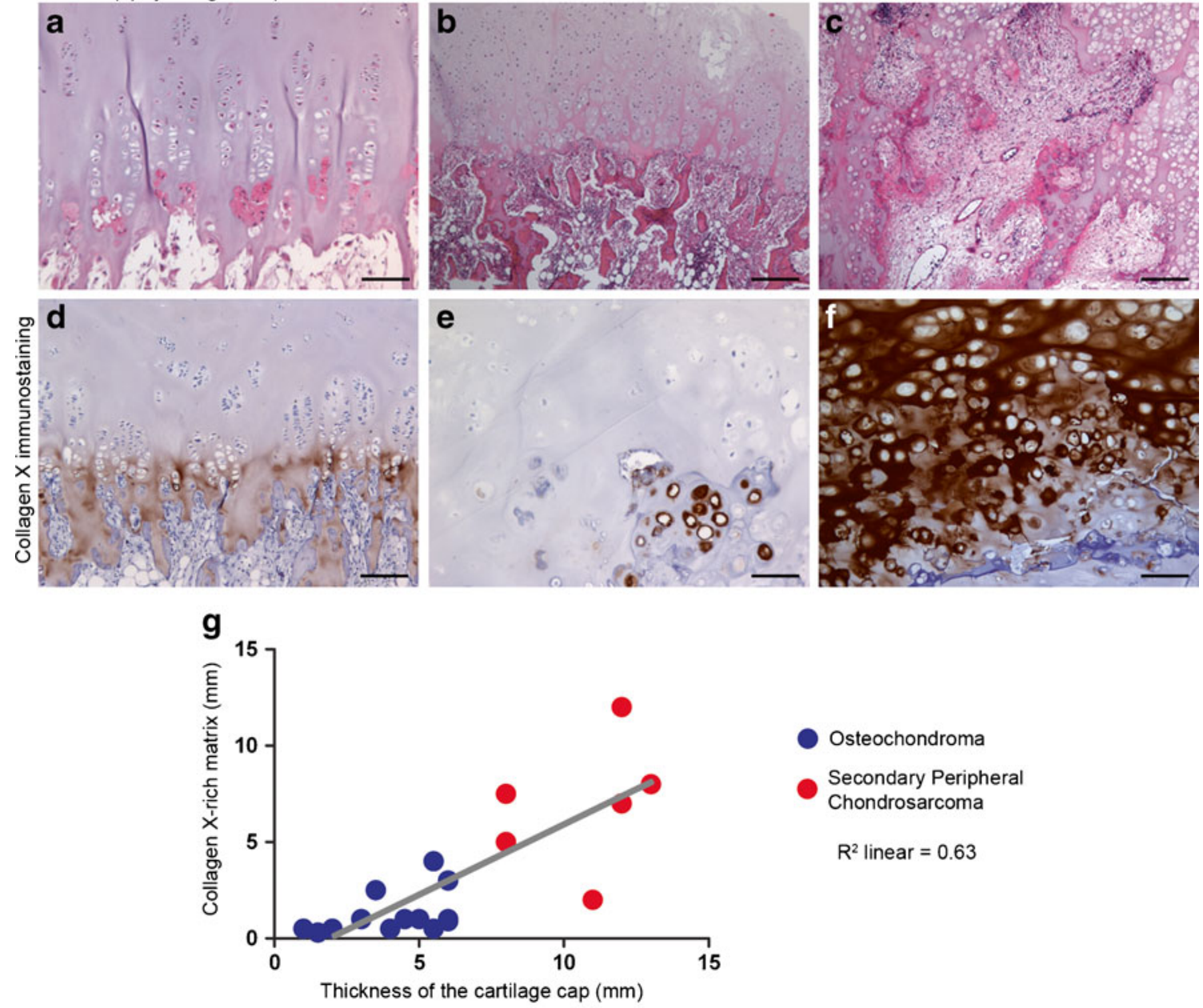

Osteochondroma

Secondary Peripheral

Chondrosarcoma

$R^{2}$ linear $=0.63$

Fig. 2 Collagen $\mathrm{X}$-rich matrix. The epiphyseal growth plate is organised in columns of stacked chondrocytes (a). Osteochondromas show less structured organisation (b), and secondary peripheral chondrosarcomas (c) display no clear organisation. Hypertrophic chondrocytes secrete a collagen X-rich matrix, which, ultimately, is replaced by bone (d). In osteochondromas, chondrocytes with a hypertrophic morphology are not always secreting collagen $\mathrm{X}(\mathbf{e})$. In secondary peripheral chondrosarcoma, a thick layer of collagen X-rich matrix is observed (f). In osteochondromas and secondary peripheral chondrosarcomas, the thickness of the cartilage cap correlates with the thickness of collagen X-rich matrix (g) (scale bars $10 \mu \mathrm{m})$ vascular density when compared to the cases with a lower proliferation rate $(0-24 \%)$; a value of $8( \pm 0.83)$ vs. 5.2 $( \pm 1.58)$ was, respectively, found $(P=0.008)$.

\section{Mutation analysis}

Fifteen of 16 patients with multiple osteochondromas demonstrated a mutation in EXT1 or EXT2 (Table 1). One patient, from whom two distinct tumours were studied (L-317 and L-332), displayed no mutations in EXT1 or EXT2. Additionally, no correlation was found between mutation type and (a) either tumour type $(P=0.564)$ (b) or the thickness of the collagen X-rich matrix $(P=0.564)$ (c) or vascular density $(P=0.556)$.

\section{Discussion}

In this study, two crucial steps of endochondral ossification, formation of a collagen X-rich matrix and invasion/ attraction of blood vessels, were assessed and compared in the epiphyseal growth plate and peripheral cartilaginous tumours (osteochondroma and secondary peripheral chondrosarcoma). The protein expression level of type X collagen in human osteochondroma was shown to be similar to the one found in human epiphyseal growth plate [4]. Interestingly, in the EXT1 heterozygous mutant mice, in situ hybridisation studies have demonstrated that the mRNA expression of type $\mathrm{X}$ collagen is reduced in the growth plate as compared to wild-type mice $[11,25]$. In 
Fig. 3 Vascular density in the ossification zone.

The epiphyseal growth plate (a, d) and secondary peripheral chondrosarcoma (c, d) show similar vascular density. Osteochondroma displays low vascular density $(\mathbf{b}, \mathbf{d})$ (asterisk indicates $P<0.05$; scale bars $5 \mu \mathrm{m})$

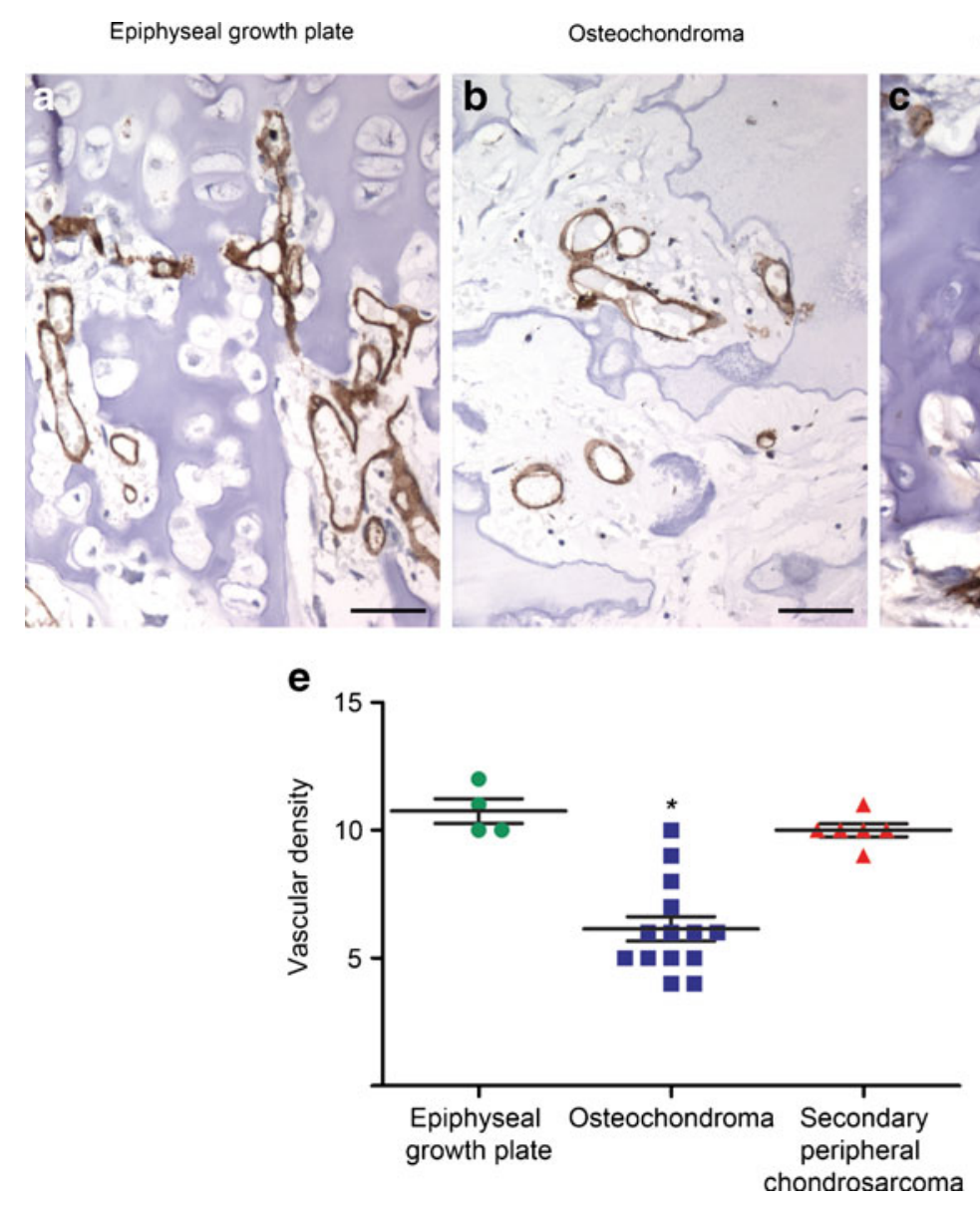

Secondary peripheral chondrosarcoma
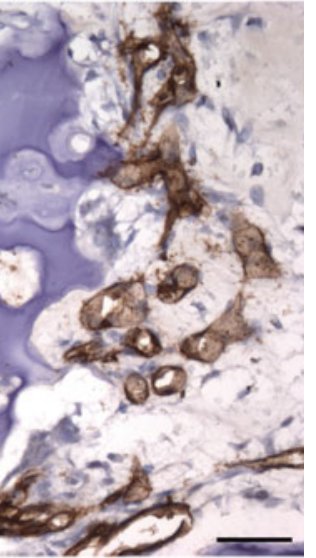
洒 
similar efficiency in attracting blood vessels as the epiphyseal growth plate.

We have recently shown that cells with functional EXT1 and EXT2 genes are the predominant subclone in secondary peripheral chondrosarcomas [9]. Therefore, the increased type X collagen deposition and blood vessel attraction in the osteocartilaginous interface of secondary peripheral chondrosarcoma are possibly associated with cells with functional EXT1 and EXT2 genes. In addition, collagen Xrich matrix formation and vascularisation might be useful prognostic markers of neoplastic transformation of an osteochondroma, but further validation is required before they can be proposed as a routine and as a reliable diagnostic tool.

In conclusion, we show that terminal chondrocyte differentiation and vascularisation are affected in osteochondromas, suggesting that EXT1 and EXT2 genes are critical for endochondral bone formation. Terminal chondrocyte differentiation and vascularisation seem to be unaffected in secondary peripheral chondrosarcomas, which might be associated with the presence of cells with functional EXT1 and EXT2 genes.

Acknowledgments This work was supported by the European network of excellence EuroBoNeT (http://www.eurobonet.eu) grant number 018814 (LSHC-CT-2006-018814).

Conflict of interest The authors declare that they have no conflict of interest.

Open Access This article is distributed under the terms of the Creative Commons Attribution Noncommercial License which permits any noncommercial use, distribution, and reproduction in any medium, provided the original author(s) and source are credited.

\section{References}

1. Kronenberg HM (2003) Developmental regulation of the growth plate. Nature 423:332-336

2. Kuhn JL, DeLacey JH, Leenellett EE (1996) Relationship between bone growth rate and hypertrophic chondrocyte volume in New Zealand white rabbits of varying ages. J Orthop Res 14:706-711

3. Ballock RT, O'Keefe RJ (2003) The biology of the growth plate. J Bone Joint Surg Am 85-A:715-726

4. Aigner T, Frischolz S, Dertinger S, Beier F, Girkontaité I, Von der Mark K (1997) Type X collagen expression and hypertrophic differentiation in chondrogenic neoplasias. Histochem Cell Biol 107:435-440

5. Khurana J, Abdul-Karim F (2002) Bovée JVMG Osteochondroma. In: Fletcher CDM, Unni KK, Mertens F (eds) World Health Organization classification of tumours. Pathology and genetics of tumours of soft tissue and bone. IARC Press, Lyon (France), pp 234-236

6. van den Berg H, Kroon HM, Slaar A, Hogendoorn P (2008) Incidence of biopsy-proven bone tumors in children: a report based on the Dutch pathology registration "PALGA". J Pediatr Orthop 28(1):29-35

7. Bovee JVMG, Hogendoorn PCW, Wunder JS, Alman BA (2010) Cartilage tumours and bone development: molecular pathology and possible therapeutic targets. Nat Rev Cancer $10: 481-488$

8. Dorfman HD, Czerniak B, Kotz R, Vanel D, Park YK, Unni KK (2002) WHO classification of tumours of bone: introduction. In: Fletcher CDM, Unni KK, Mertens F (eds) World Health Organization classification of tumours. Pathology and genetics of tumours of soft tissue and bone. IARC Press, Lyon, pp 226232

9. de Andrea CE, Reijnders CM, Kroon HM, de Jong D, Hogendoorn PC, Szuhai K et al (2011) Secondary peripheral chondrosarcoma evolving from osteochondroma as a result of outgrowth of cells with functional EXT. Oncogene. doi:10.1038/onc.2011.311

10. Kucharzewska P, Welch JE, Birgersson J, Belting M (2010) Establishment of heparan sulphate deficient primary endothelial cells from EXT-1(flox/flox) mouse lungs and sprouting aortas. In Vitro Cell Dev Biol Anim 46:577-584

11. Hilton MJ, Gutierrez L, Martinez DA, Wells DE (2005) EXT1 regulates chondrocyte proliferation and differentiation during endochondral bone development. Bone 36:379-386

12. Wiweger MI, Avramut CM, de Andrea CE, Prins FA, Koster AJ, Ravelli RB et al (2011) Cartilage ultrastructure in proteoglycan-deficient zebrafish mutants brings to light new candidate genes for human skeletal disorders. J Pathol 223:531542

13. Hufnagel L, Kreuger J, Cohen SM, Shraiman BI (2006) On the role of glypicans in the process of morphogen gradient formation. Dev Biol 300:512-522

14. Hacker U, Nybakken K, Perrimon N (2005) Heparan sulphate proteoglycans: the sweet side of development. Nat Rev Mol Cell Biol 6:530-541

15. Reijnders CM, Waaijer CJ, Hamilton A, Buddingh' EP, Dijkstra SP, Ham J et al (2010) No haploinsufficiency but loss of heterozygosity for EXT in multiple osteochondromas. Am J Pathol 177:1946-1957

16. Verbeke SL, Fletcher CD, Alberghini M, Daugaard S, Flanagan AM, Parratt $T$ et al (2010) A reappraisal of hemangiopericytoma of bone; analysis of cases reclassified as synovial sarcoma and solitary fibrous tumor of bone. Am J Surg Pathol 34:777-783

17. Schrage YM, Machado I, Meijer D, Briaire-de Bruijn I, van den Akker B, Taminiau AHM et al (2010) COX-2 expression in chondrosarcoma: a role for celecoxib treatment? Eur J Cancer 46:616-624

18. de Andrea CE, Wiweger M, Prins F, Bovee JVMG, Romeo S, Hogendoorn PCW (2010) Primary cilia organization reflects polarity in the growth plate and implies loss of polarity and mosaicism in osteochondroma. Lab Invest 90:1091-1101

19. Vermeulen PB, Gasparini G, Fox SB, Toi M, Martin L, McCulloch P et al (1996) Quantification of angiogenesis in solid human tumours: an international consensus on the methodology and criteria of evaluation. Eur J Cancer 32A:2474 2484

20. Hansen S, Grabau DA, Sorensen FB, Bak M, Vach W, Rose C (2000) The prognostic value of angiogenesis by Chalkley counting in a confirmatory study design on 836 breast cancer patients. Clin Cancer Res 6:139-146

21. Vink GR, White SJ, Gabelic S, Hogendoorn PCW, Breuning MH, Bakker E (2004) Mutation screening of EXT1 and EXT2 by direct sequence analysis and MLPA in patients with multiple osteochondromas: splice site mutations and exonic deletions account for more than half of the mutations. Eur J Hum Genet 13:470-474 
22. White SJ, Vink GR, Kriek M, Wuyts W, Schouten J, Bakker B et al (2004) Two-color multiplex ligation-dependent probe amplification: detecting genomic rearrangements in hereditary multiple exostoses. Hum Mutat 24:86-92

23. Bovee JVMG, Cleton-Jansen AM, Wuyts W, Caethoven G, Taminiau AHM, Bakker E et al (1999) EXT-mutation analysis and loss of heterozygosity in sporadic and hereditary osteochondromas and secondary chondrosarcomas. Am J Hum Genet 65:689-698

24. Hameetman L, David G, Yavas A, White SJ, Taminiau AHM, Cleton-Jansen AM et al (2007) Decreased EXT expression and intracellular accumulation of HSPG in osteochondromas and peripheral chondrosarcomas. J Pathol 211:399-409
25. Koziel L, Kunath M, Kelly OG, Vortkamp A (2004) EXT1dependent heparan sulfate regulates the range of Ihh signaling during endochondral ossification. Dev Cell 6:801-813

26. Iozzo RV (2001) Heparan sulfate proteoglycans: intricate molecules with intriguing functions. J Clin Invest 108:165167

27. Bernfield M, Gotte M, Park PW, Reizes O, Fitzgerald ML, Lincecum J et al (1999) Functions of cell surface heparan sulfate proteoglycans. Annu Rev Biochem 68:729-777

28. Chen E, Hermanson S, Ekker SC (2004) Syndecan-2 is essential for angiogenic sprouting during zebrafish development. Blood 103:1710-1719 